\title{
A Common Uptake System for Serotonin and Dopamine
}

\section{in Human Platelets}

\author{
Gilbert S. OMENN and LynNe T. SMith, Department of Medicine, Division \\ of Medical Genetics, University of Washington, Seattle, Washington 98195
}

\begin{abstract}
A в S T R A C T Kinetic and pharmacologic properties of uptake of serotonin and dopamine by normal human platelets have been investigated to test whether platelets can be employed as a model system for the reuptake of serotonin and dopamine in brain. Uptake of serotonin into platelets closely resembles reuptake of serotonin into serotonergic neurons. In contrast, uptake of dopamine into platelets appears to be mediated inefficiently via the specific serotonin uptake mechanism, based upon several lines of evidence. Serotonin and dopamine compete with each other. Antidepressant drugs, which are competitive inhibitors of uptake of both of these neurotransmitters, act at the same concentration of drug despite large differences in the $K_{m}$ values. Serotonin antagonists inhibit both serotonin and dopamine uptake. Finally, a serotoninspecific uptake inhibitor (fluoxetine) blocks dopamine, as well as serotonin, uptake.
\end{abstract}

\section{INTRODUCTION}

There is considerable evidence that platelets may serve as model systems for uptake, binding, and release of neurotransmitter monoamines in nerve endings in the brain and the peripheral nervous system (1-3). Reuptake into the presynaptic neuron of released neurotransmitter is the most important step in controlling the intrasynaptic concentration and neural effects of monoamine neurotransmitters $(4,5)$. In addition, neuronal reuptake is a major site of action for tricyclic antidepressants, amphetamines, and antihistaminic drugs $(6,7)$.

Human platelets actively take up serotonin (5-hydroxytryptamine, $5 \mathrm{HT}),{ }^{1}$ store it in electron-dense

Dr. Omenn was an Investigator of the Howard Hughes Medical Institute.

Received for publication 5 July 1977 and in revised form 23 March 1978.

${ }^{1}$ Abbreviations used in this paper: DA, dopamine; 5HT, 5-hydroxytryptamine, serotonin; $I_{50}$, concentration of inhibitor that produces $50 \%$ inhibition; $\mathrm{PRP}$, platelet-rich plasma; $\mathrm{S}$, substrate concentration; $\mathrm{V}$, velocity. granules as molecular aggregates with ATP and $\mathrm{Ca}^{++}$, and release 5HT together with adenine nucleotides and other platelet factors upon stimulation (8). The high-affinity uptake system for serotonin has kinetic constants similar to those reported for animal brain synaptosome preparations $(9,10)$, and tricyclic dibenzazepine antidepressants and amphetamines, which inhibit neuronal reuptake of 5HT and catecholamines, also inhibit 5HT uptake into platelets $(10,11)$.

Other compounds of neurochemical interest are concentrated by platelets, including dopamine, norepinephrine, octopamine, taurine, and choline (12-16). The significance of uptake of these compounds is uncertain , because the concentration gradients are very much less than for $5 \mathrm{HT}$ and the uptake is not readily saturated. There is no proof that the uptake mechanisms in platelets are identical with those in brain. Nevertheless, the platelet system has been employed in a number of clinical investigations of the potential roles of dopamine (DA) and 5HT. Uptake of DA has been reported to be increased in Huntington's disease (17) and decreased in parkinsonism (18). Abnormalities in platelet uptake of 5HT have been claimed for Down's syndrome (19-22), Huntington's disease (17), depression (23), and Duchenne's muscular dystrophy (24), and reduced platelet $5 \mathrm{HT}$ content has been demonstrated in Down's syndrome, phenylketonuria (25, 26) and such platelet storage-pool disorders as Hermansky-Pudlak type of oculocutaneous albinism (27). Inferences have been drawn about possible abnormalities in the brain involving 5HT and DA in these patients.

We have investigated certain properties of 5HT and DA uptake into platelets from normal human subjects. Pharmacological and kinetic results presented here indicate that the uptake of DA into platelets is mediated through 5HT channels, rather than through an independent transport mechanism for DA.

\section{METHODS}

Subjects. Human subjects provided 10- to 20-ml samples of venous blood after informed written consent. Subjects 
were normal volunteers including normal relatives of patients studied with various neurological and genetic disorders. Record was made of any medications taken by the person.

Materials. $\left[{ }^{3} \mathrm{H}\right] 5 \mathrm{HT} \cdot$ creatinine sulfate $(16 \mathrm{Ci} / \mathrm{mmol})$ was obtained from Amersham/Searle Corp. (Arlington Heights, Ill.) and $\left[{ }^{3} \mathrm{H}\right] \mathrm{DA}(7.5 \mathrm{Ci} / \mathrm{mmol})$ and $\left[{ }^{14} \mathrm{C}\right]$ inulin $(50 \mu \mathrm{Ci} / 10 \mathrm{ml})$ from New England Nuclear (Boston, Mass.). 3-( $p$-Trifluoromethylphenoxy)- $N$-methyl-3-phenylpropylamine (fluoxetine) was provided by Dr. Ray W. Fuller of Eli Lilly Company (Indianapolis, Ind.). Cyproheptadine $\cdot \mathrm{HCl}$, methysergide maleate, and L-amphetamine succinate were gifts from Merck Sharp \& Dohme, Canada Ltd. (Montreal, Canada); Sandoz Pharmaceuticals (Hanover, N. J.); and CORD Labofactories, Inc. (Detroit, Mich.), respectively. Doxepin, nortriptyline, and imipramine as $\mathrm{HCl}$ salts were provided by Dr. R. O. Friedel, Department of Psychiatry and Behavioral Sciences, University of Washington. Benztropine mesylate was purchased from Merck Sharpe \& Dohme; haloperidol from McNeil Laboratories (Fort Washington, Pa.); and D-amphetamine sulfate and all other chemicals from Sigma Chemical Co. (St. Louis, Mo.).

Preparation of platelet-rich plasma (PRP). Whole venous blood collected with $K_{3}$-EDTA as anticoagulant (final concentration $=4 \mathrm{mM}$ ) was centrifuged at $200 \mathrm{~g}$ for $10 \mathrm{~min}$ at room temperature. EDTA was selected as anticoagulant because platelet counts and platelet uptake of $5 \mathrm{HT}$ were stable longer than with heparin or sodium citrate as anticoagulants. Samples kept at room temperature gave constant $K_{m}$ values up to $6 \mathrm{~h}$; all studies were completed within $4 \mathrm{~h}$ of venipuncture. An aliquot of the PRP was counted in a Coulter counter (Coulter Electronics Inc., Hialeah, Fla.), model $\mathrm{Z}_{\mathrm{B} 1}$; counts

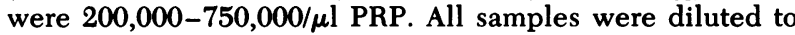
a concentration of 200,000 platelets/ $\mu$ l with Krebs-bicarbonate buffer, $\mathrm{pH} 7.4\left(143 \mathrm{mM} \mathrm{Na}{ }^{+}\right)$, equilibrated before use with $95 \% \mathrm{O}_{2}-5 \% \mathrm{CO}_{2} . \mathrm{Mg}^{++}$and $\mathrm{Ca}^{++}$were omitted from the buffer. Dilution with buffer instead of with plasma diminished $\mathrm{V}_{\max }$ values, but had no effect on apparent $K_{m}$ values.

Measurement of platelet uptake of 5HT and DA. Uptake experiments were performed in 400- $\mu$ l Beckman plastic microfuge tubes (Beckman Instruments, Inc., Fullerton, Calif.) with a total reaction mixture volume of $250 \mu \mathrm{l} .50 \mu \mathrm{l}$ $\left[{ }^{3} \mathrm{H}\right] 5 \mathrm{HT}$ of appropriate concentration (stock prepared in five concentrations for determination of $K_{m}$ ) plus $150 \mu \mathrm{l}$ total volume of Krebs-bicarbonate buffer and inhibitor were mixed at room temperature; then a ring of $50 \mu$ l PRP was layered above. The reaction was started immediately by shaking the capped tubes and placing them in a $37^{\circ} \mathrm{C}$ bath. Uptake was linear for $5 \mathrm{~min}$, after which time the uptake reaction was terminated by centrifugation in a microfuge (Beckman model 152) for $30 \mathrm{~s}$ at $12,000 \mathrm{rpm}$. The tube was refilled with buffer and centrifuged; the tube tip containing the tube was then sliced into a scintillation counting vial. The sample was solubilized with $0.2 \mathrm{ml}$ Soluene 100 (Packard Instrument Co. Inc., Downers Grove, Ill.). Omnifluor (New England Nuclear) in toluene was used as the scintillant, and samples were counted at room temperature in a Packard model 2002 liquid scintillation spectrometer.

An identical procedure was employed for uptake of $\left[{ }^{3} \mathrm{H}\right] \mathrm{DA}$, except that incubations were carried out for $10 \mathrm{~min}$, and platelet concentration was doubled to $2 \times 10^{7} / 250 \mu$ l reaction mixture. Uptake was linear for $20 \mathrm{~min}$. Freshly prepared solutions of $\left[{ }^{3} \mathrm{H}\right] \mathrm{DA}$ were employed because DA undergoes oxidative decomposition in mildly alkaline solution. Stock solutions of DA were kept under $\mathrm{N}_{2}$ and were checked by thin-layer chromatography with $n$-butanol, acetic acid, and water $(25: 4: 10)$. Ascorbic acid $(0.1 \mathrm{mg} / \mathrm{ml})$ was present in all solutions and reaction mixtures containing DA.

Because initial rates of uptake were not affected by the presence of inhibitors of monoamine oxidase $(10 \mu \mathrm{M}$ pargyline or $10 \mu \mathrm{M}$ nialamide), these compounds were omitted.

The extent to which $\left[{ }^{3} \mathrm{H}\right] 5 \mathrm{HT}$ and $\left[{ }^{3} \mathrm{H}\right] \mathrm{DA}$ might be entrapped in the intercellular spaces of the washed platelet pellet was determined. PRP incubated with $\left[{ }^{14} \mathrm{C}\right]$ inulin instead of $\left[{ }^{3} \mathrm{H}\right] 5 \mathrm{HT}$ or $\left[{ }^{3} \mathrm{H}\right] \mathrm{DA}$ retained $<0.01$ and $0.02 \%$ of counts in the platelet pellets from 50 and $100 \mu \mathrm{l}$ of PRP after 5 and $10 \mathrm{~min}$, respectively. Results of uptake measurements were corrected for these amounts of entrapped extracellular volume.

Inhibition of uptake by pharmacological agents. Selected drugs were added to the incubation medium with $\left[{ }^{3} \mathrm{H}\right] 5 \mathrm{HT}$ or $\left[{ }^{3} \mathrm{H}\right] \mathrm{DA}$ and then mixed with the PRP at the start of the reaction to limit the effect of the drug to competition for binding sites. A range of concentrations was employed to demonstrate the extent of maximal inhibition and the possibility of more than one component of inhibition, using a Dixon plot of velocity $(1 / \mathrm{V})$ vs. substrate concentration(s) of inhibitor. Then a concentration producing approximately $50 \%$ inhibition was used in experiments with PRP from test subjects, using $\left[{ }^{3} \mathrm{H}\right] 5 \mathrm{HT}$ or $\left[{ }^{3} \mathrm{H}\right] \mathrm{DA}$ at several different concentrations to permit analysis of inhibition constants $\left(K_{i}\right)$ from a Lineweaver-Burk plot $(1 / \mathrm{V}$ vs. $1 / \mathrm{S})$. These plots also served to distinguish competitive and noncompetitive inhibition. Kinetic parameters were calculated by standard methods.

\section{RESULTS}

Platelet uptake of 5HT. Fig. 1A presents typical results for the uptake of $\left[{ }^{3} \mathrm{H}\right] 5 \mathrm{HT}$ by human platelets. The reciprocal plot (Fig. 1B) indicates a single-component high-affinity uptake mechanism with an apparent $K_{m}$ of $0.42 \mu \mathrm{M}$ and a $V_{\max }$ of $8.8 \mathrm{pmol} / 10^{7}$ platelets per $5 \mathrm{~min}$. Uptake at $0^{\circ} \mathrm{C}$ is minimal.

To assess intraindividual variation, one subject (G. S. O.) provided samples at 11 times over a period of $18 \mathrm{mo}$, including various times of day and various intervals after eating. The intraindividual variation
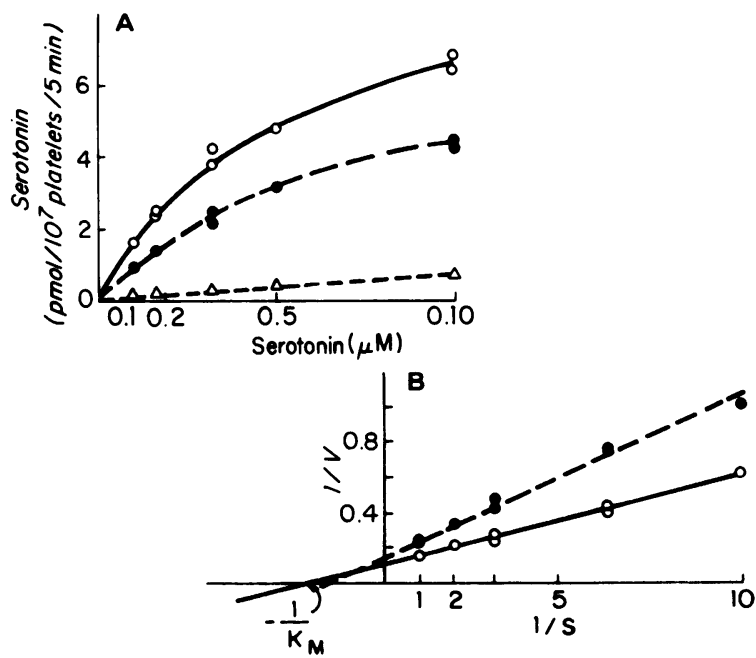

FIGURE 1 Uptake of 5HT by human platelets. (A) Plot of amount of uptake (V) vs. substrate concentration (S) of 5HT at $37^{\circ} \mathrm{C}(O)$, at $0^{\circ} \mathrm{C}(\Delta)$, and in the presence of $10 \mathrm{nM}$ imipramine (O). (B) Lineweaver-Burk plot, (1/V) vs. (1/S). 
comprises technical and potential physiological sources of variation. The apparent $K_{m}$ was $0.34 \pm 0.02 \mu \mathrm{M}$ (mean $\pm \mathrm{SEM}$ ), and the $\mathrm{V}_{\max }$ was $8.1 \pm 0.8 \mathrm{pmol} / 10^{7}$ platelets per $5 \mathrm{~min}$; the range in $K_{m}$ values was $0.27-0.42 \mu \mathrm{M}$. For 54 normal subjects, the apparent $K_{m}$ was $0.40 \pm 0.02$ $\mu \mathrm{M}$ and the $\mathrm{V}_{\max } 10.2 \pm 1.0 \mathrm{pmol} / 10^{7}$ platelets per $5 \mathrm{~min}$.

Platelet uptake of DA. Platelet uptake of DA is considerably less avid than that of 5HT. For 20 normal subjects, the apparent $K_{m}$ was $49 \pm 4 \mu \mathrm{M}$ and the $\mathrm{V}_{\max }$ $52 \pm 9 \mathrm{pmol} / 2 \times 10^{7}$ platelets per $10 \mathrm{~min}$. Typical results are plotted in Fig. 2. Concentrations of 0.01-1 $\mu \mathrm{M}$ DA failed to give significant uptake.

Competition between 5HT and DA. Unlabeled $5 \mathrm{HT}$ and DA inhibit the uptake of $\left[{ }^{3} \mathrm{H}\right] 5 \mathrm{HT}$ and of $\left[{ }^{3} \mathrm{H}\right] \mathrm{DA}$, respectively. In addition, $5 \mathrm{HT}$ competitively inhibits uptake of $\left[{ }^{3} \mathrm{H}\right] \mathrm{DA}$, and DA competitively inhibits the uptake of $\left[{ }^{3} \mathrm{H}\right] 5 \mathrm{HT}$ (Fig. 3). Half-maximal inhibition of $\left[{ }^{3} \mathrm{H}\right] \mathrm{DA}$ uptake $\left(\left[{ }^{3} \mathrm{H}\right] \mathrm{DA}\right.$ concentration $=2.5 \mu \mathrm{M}$ ) occurred with $5 \mathrm{HT}$ at $0.5 \mu \mathrm{M}$. Maximal inhibition was obtained at $1 \mathrm{mM}$, reducing $\left[{ }^{3} \mathrm{H}\right] \mathrm{DA}$ uptake to $20 \%$ of control values. Unlabeled DA inhibited $\left[{ }^{3} \mathrm{H}\right] 5 \mathrm{HT}$ uptake by only $10 \%$ at $10 \mu \mathrm{M}$ but by $90-96 \%$ at $1 \mathrm{mM}$. Half-maximal inhibition $\left(\mathrm{I}_{50}\right)$ occurred with DA at $0.1 \mathrm{mM}$, corresponding to an inhibition constant of about $6 \mu \mathrm{M}$, because $\mathrm{I}_{50}=k_{i}\left(1+\mathrm{S} / \mathrm{K}_{m}\right)$, where $\mathrm{S}$ and $K_{m}$ refer to the concentration and $K_{m}$ of 5HT (28).

Inhibition of uptake by drugs. The effects of a series of antidepressant agents on platelet uptake of $\left[{ }^{3} \mathrm{H}\right] 5 \mathrm{HT}$ and $\left[{ }^{3} \mathrm{H}\right] \mathrm{DA}$ are given in Table I. All of these agents are known to be potent inhibitors of biogenic amine reuptake in brain $(6,7)$. Inhibition curves as a
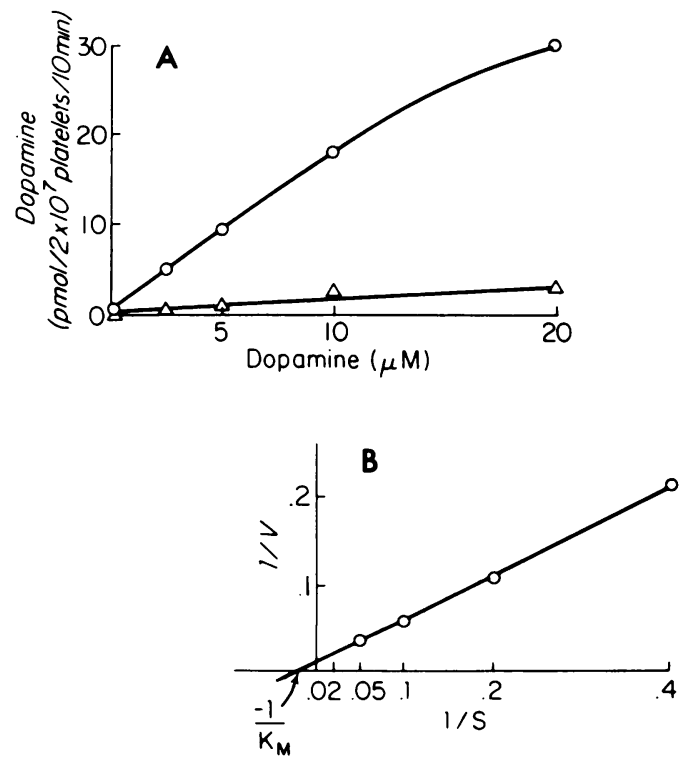

Figure 2 Uptake of DA by human platelets. (A) Plot of amount of uptake (V) vs. concentration (S) of DA at $37^{\circ} \mathrm{C}$ $(O)$ and at $0^{\circ} \mathrm{C}(\triangle)$. (B) Lineweaver-Burk plot, $(1 / \mathrm{V})$ vs. (1/S).
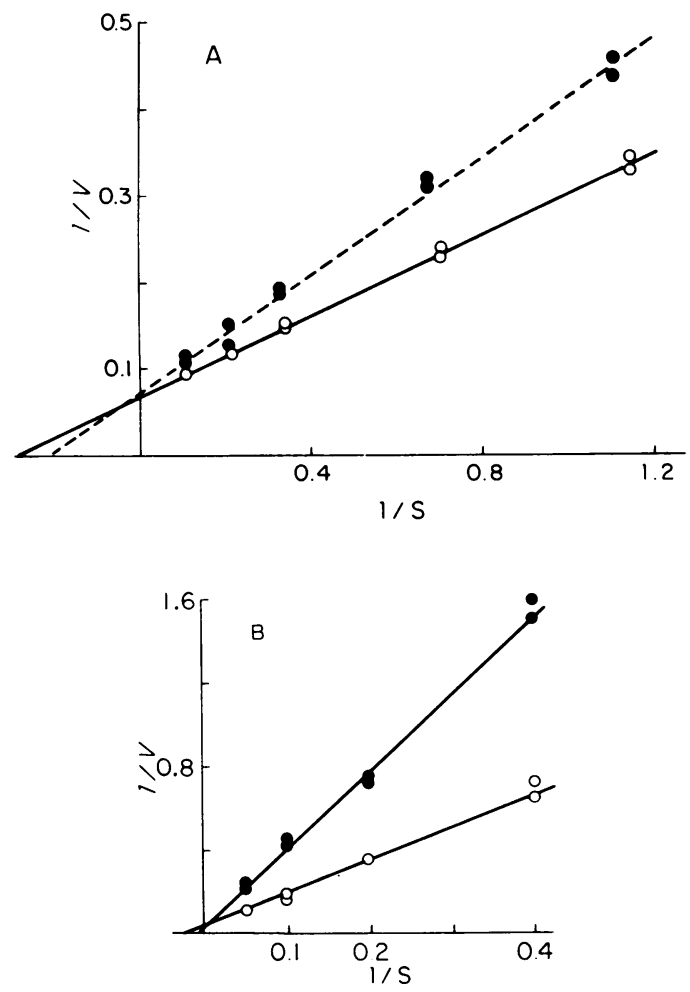

FIgURE 3 Cross-inhibition of competitive type between 5HT and DA. (A) Inhibition of uptake of $\left[{ }^{3} \mathrm{H}\right] 5 \mathrm{HT}$ by $0.1 \mathrm{mM}$ DA. (B) Inhibition of uptake of $\left[{ }^{3} \mathrm{H}\right] \mathrm{DA}$ by $10 \mu \mathrm{M}$ 5HT. Control uptake $(\mathrm{V})$ of each labeled compound $(O)$ and uptake in the presence of DA (O), A, or $5 \mathrm{HT}(\Theta) \mathrm{B}$, respectively, as inhibitors. Concentration, $(S)$ or $\left[{ }^{3} \mathrm{H}\right] 5 \mathrm{HT}$ ranges from 0.1 to $1.0 \mu \mathrm{M}$ and of $\left[{ }^{3} \mathrm{H}\right] \mathrm{DA}$ ranges from 2.5 to $20 \mu \mathrm{M}$.

function of drug concentration show imipramine $>$ doxepin $>$ D-amphetamine in relative potency. All of these drugs produced competitive inhibition. The estimated inhibition constants for each drug against 5HT and DA uptake were nearly identical, indicating that the site of inhibition is the same.

TABLE I

Inhibition of Platelet Uptake of 5HT and DA by Antidepressant Drugs

\begin{tabular}{|c|c|c|c|c|}
\hline \multirow[b]{2}{*}{ Inhibitor } & \multicolumn{2}{|c|}{$\begin{array}{l}\text { Concentration giving } \\
50 \% \text { of maximal } \\
\text { inhibition }\end{array}$} & \multicolumn{2}{|c|}{$\begin{array}{l}\text { Maximal inhibition } \\
\text { at } 0.1 \mathrm{mM} \text { inhibitor }\end{array}$} \\
\hline & $\begin{array}{l}{\left[{ }^{3} \mathrm{H}\right] 5 \mathrm{HT}} \\
\text { uptake }\end{array}$ & $\begin{array}{c}{\left[{ }^{3} \mathrm{H}\right] \mathrm{DA}} \\
\text { uptake }\end{array}$ & $\begin{array}{c}{\left[{ }^{3} \mathrm{H}\right] 5 \mathrm{HT}} \\
\text { uptake }\end{array}$ & $\begin{array}{c}{\left[{ }^{3} \mathrm{H}\right] \mathrm{DA}} \\
\text { uptake }\end{array}$ \\
\hline & & & \multicolumn{2}{|c|}{$\%$} \\
\hline Imipramine & $10 \mathrm{nM}$ & $6 \mathrm{nM}$ & 97 & 60 \\
\hline Nortriptyline & $0.1 \mu \mathrm{M}$ & $0.06 \mu \mathrm{M}$ & 90 & 60 \\
\hline Doxepin & $0.4 \mu \mathrm{M}$ & $0.2 \mu \mathrm{M}$ & 97 & 60 \\
\hline D-Amphetamine & $8 \mu \mathrm{M}$ & $6 \mu \mathrm{M}$ & 96 & 60 \\
\hline
\end{tabular}

Experiments employ: $5 \mathrm{HT}=0.2 \mu \mathrm{M} ; \mathrm{DA}=2.5 \mu \mathrm{M}$. 
TABLE II

Pharmacologic Agents to Distinguish 5HT and DA Uptake in Platelets

\begin{tabular}{|c|c|c|c|c|}
\hline \multirow[b]{2}{*}{ Inhibitor } & \multicolumn{2}{|c|}{$\begin{array}{l}\text { Concentration giving } \\
50 \% \text { of maximal } \\
\text { inhibition }\end{array}$} & \multicolumn{2}{|c|}{$\begin{array}{l}\text { Maximal inhibition } \\
\text { at } 1 \mathrm{mM} \text { inhibitor }\end{array}$} \\
\hline & $\begin{array}{c}{\left[{ }^{3} \mathrm{H}\right] 5 \mathrm{HT}} \\
\text { uptake }\end{array}$ & $\begin{array}{l}{\left[{ }^{3} \mathrm{H}\right] \mathrm{DA}} \\
\text { uptake }\end{array}$ & $\begin{array}{c}{\left[{ }^{3} \mathrm{H}\right] 5 \mathrm{HT}} \\
\text { uptake }\end{array}$ & $\begin{array}{l}{\left[{ }^{3} \mathrm{H}\right] \mathrm{DA}} \\
\text { uptake }\end{array}$ \\
\hline & & & \multicolumn{2}{|c|}{$\%$} \\
\hline Methysergide & $70 \mu \mathrm{M}$ & $120 \mu \mathrm{M}$ & 73 & 64 \\
\hline Cyproheptadine & $20 \mu \mathrm{M}$ & $30 \mu \mathrm{M}$ & 98 & 60 \\
\hline Haloperidol & $30 \mu \mathrm{M}$ & $40 \mu \mathrm{M}$ & 96 & 65 \\
\hline Fluoxetine & $7 \mathrm{nM}$ & $10 \mathrm{nM}$ & 98 & 80 \\
\hline
\end{tabular}

Experiments employ: $5 \mathrm{HT}=0.2 \mu \mathrm{M} ; \mathrm{DA}=2.5 \mu \mathrm{M}$.

Drugs that act as specific antagonists of $5 \mathrm{HT}$ or of DA in other organs were tested in this platelet system (Table II). The 5HT antagonists, methysergide and cyproheptadine, produced similar curves of inhibition for both 5HT and DA. These drugs completely blocked $5 \mathrm{HT}$ uptake at very high concentrations $(98 \%$ at $1 \mathrm{mM})$. The potent DA antagonist haloperidol had no effect on either $\left[{ }^{3} \mathrm{H}\right] 5 \mathrm{HT}$ or $\left[{ }^{3} \mathrm{H}\right] \mathrm{DA}$ uptake at low concentrations of drug, but gave identical inhibition of both compounds at high concentrations (Table II). Benztropine, a potent and specific inhibitor of DA reuptake in rat corpus striatum with an $I_{50}$ of $0.1-0.3 \mu \mathrm{M}(29$, 30 ), had no effect on platelet uptake of either labeled compound at concentrations up to $10 \mu \mathrm{M}$, though 15$25 \%$ inhibition was achieved at $1 \mathrm{mM}$. In striking contrast, fluoxetine, a drug that is a highly selective inhibitor of 5HT reuptake in rat brain (31), proved to be a very potent inhibitor of uptake of both $\left[{ }^{3} \mathrm{H}\right] 5 \mathrm{HT}$ and $\left.{ }^{3} \mathrm{H}\right] \mathrm{DA}$ into platelets (Table II, Fig. 4). Inhibition

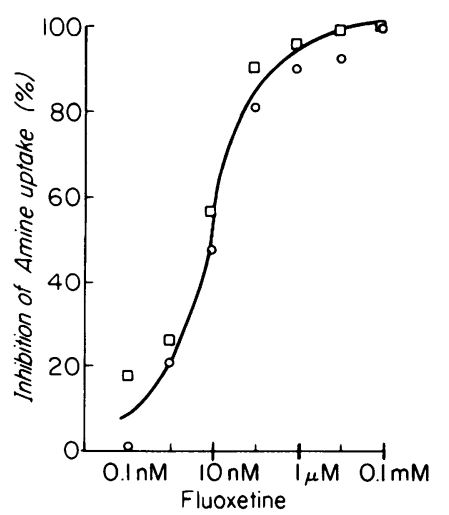

FIGURE 4 Inhibition of uptake of $\left[{ }^{3} \mathrm{H}\right]$ serotonin $(0.2 \mu \mathrm{M})$ ( $\square$ ) and of $\left[{ }^{3} \mathrm{H}\right] \mathrm{DA}(2.5 \mu \mathrm{M})(\bigcirc)$ into human platelets by fluoxetine, a selective inhibitor of serotonin reuptake in brain. DA uptake was corrected for $20 \%$ nonsaturable uptake, not inhibitable by $1 \mathrm{mM}$ fluoxetine. was of the competitive type, with half-maximal inhibition in each case about $10 \mathrm{nM}$. With concentrations of $\left[{ }^{3} \mathrm{H}\right] \mathrm{DA}$ from 2.5 to $25 \mu \mathrm{M}, 10 \mathrm{nM}$ fluoxetine inhibited $50-55 \%$ of the saturable uptake.

\section{DISCUSSION}

The platelet offers an accessible tissue for studies of biogenic amines, including studies of the effects of uptake-inhibiting drugs. Uptake of 5HT appears to be a good model for the $\mathrm{Na}^{+}$-dependent active reuptake of 5HT into serotonergic neurons in brain (3). The $K_{m}$ for uptake and the inhibition constants for a number of uptake-inhibiting drugs are closely similar in platelets and in brain. In other studies, we have examined platelets and brain synaptosomes from the same individuals. Because fresh synaptosomes could not be prepared from donors of the human blood samples, these comparisons have been carried out with mice (32) and with monkeys (33). Certain differences in the kinetics of uptake in vitro were found, including a second high-affinity uptake component in synaptosomes which is reversibly inhibited by a dialyzable factor in plasma. Kinetic variants between individuals or between strains were not found, so stringent genetic criteria for identity or differences have not yet been met.

In contrast with the brain/platelet comparisons for 5HT, it is becoming clear from our own work and from published studies $(3,34-36)$ that the uptake characteristics for DA in platelets are far different from those in brain, which has an apparent $K_{m}$ of 0.1-0.4 $\mu \mathrm{M}(29$, 37-39). The apparent $K_{m}$ for platelet uptake of DA is $50 \mu \mathrm{M}$; thus, the avidity of platelets is some 500 times less than that of synaptosomes from brain regions, and the concentrations required to achieve measurable uptake into platelets are associated with a substantial amount of nonsaturable uptake.

Platelet uptake of DA appears to be mediated through the 5HT channels. 5HT and DA compete with each other for transport, with half-maximal inhibition at concentrations similar to their respective $K_{m}$ s for uptake. Various antidepressant drugs, which are competitive inhibitors of uptake of both 5HT and DA in brain, inhibit platelet uptake at the same concentrations of drug, despite the large difference in $K_{m}$ values for 5HT and DA. 5HT antagonists affect both 5HT and DA uptake. Finally, a specific inhibitor of 5HT uptake, fluoxetine, blocks uptake of DA equally well in platelets. It is conceivable that the common uptake mechanism is at the storage granule membrane rather than the plasma membranes of the platelet, but the immediate actions of the uptake-inhibiting drugs are probably localized to the plasma membrane. All estimations of the effects of the uptake-inhibiting drugs were made on the basis of maximal inhibition of the saturable uptake. At concentrations of DA in the $10 \mu \mathrm{M}$ to $100 \mu \mathrm{M}$ 
range, nonsaturating uptake must be subtracted, as in the method of Tuomisto (11). In various sets of experiments, $20-40 \%$ of the total uptake was noninhibitable by high concentrations of inhibitors (Tables I and II).

These results have implications for interpretations of clinical investigations of 5HT and DA uptake into platelets of patients with specific disorders. Reports of abnormal DA uptake into platelets in Huntington's disease (17) and parkinsonism (18) must be reassessed. If DA uptake is mediated through the 5HT mechanism, it is preferable to analyze $5 \mathrm{HT}$ uptake characteristics because the complications of passive entry of DA can be avoided. We have done so in a study of patients and persons at risk for Huntington's disease and found them to have normal kinetics of uptake (40).

\section{REFERENCES}

1. Paasonen, M. K. 1965. Release of 5-hydroxytryptamine from blood platelets. J. Pharm. Pharmacol. 17: 681-697.

2. Pletscher, A. 1968. Metabolism, transfer and storage of 5-hydroxytryptamine in blood platelets. $\mathrm{Br}$. J. Pharmacol. 32: $1-16$.

3. Sneddon, J. M. 1973. Blood platelets as a model for monoamine-containing neurones. Prog. Neurobiol. (N. Y.). 1: $151-198$.

4. Axelrod, J. 1965. The metabolism, storage, and release of catecholamines. Recent Prog. Horm. Res. 21: 597-619.

5. Iversen, L. L. 1967. The Uptake and Storage of Noradrenaline in Sympathetic Nerves. Cambridge University Press, New York. 253 pp.

6. Coyle, J. T., and S. H. Snyder. 1969. Catecholamine uptake by synaptosomes in homogenates of rat brain: Stereospecificity in different areas. J. Pharmacol. Exp. Ther. 170: $221-231$.

7. Lidbrink, P., G. Jonsson, and K. Fuxe. 1971. The effect of imipramine-like drugs and antihistamine drugs on uptake mechanisms in the central noradrenaline and 5-hydroxytryptamine neurons. Neuropharmacology. 10: $521-536$.

8. Weiss, H. J. 1975. Platelet physiology and abnormalities of platelet function. N. Engl. J. Med. 293: 531-541, 580588.

9. Shaskan, E. G., and S. H. Snyder. 1970. Kinetics of serotonin accumulation into slices from rat brain: Relationship to catecholamine uptake. J. Pharmacol. Exp. Ther. 175: 404-418.

10. Wong, D. T., J-S. Horng, and R. W. Fuller. 1973. Kinetics of serotonin accumulation into synaptosomes of rat brain-effects of amphetamine and chloroamphetamines. Biochem. Pharmacol. 22: 311-322.

11. Tuomisto, J. 1974. A new modification for studying 5-HT uptake by blood platelets: A re-evaluation of tricyclic antidepressants as uptake inhibitors. J. Pharm. Pharmacol. 26: $92-100$.

12. Boullin, D. J., and R. A. O'Brien. 1970. Accumulation of dopamine by blood platelets from normal subjects and parkinsonian patients under treatment with L-DOPA. Br. J. Pharmacol. 39: 779-788.

13. Born, G. V. R., and J. B. Smith. 1970. Uptake, metabolism and release of $\left[{ }^{3} \mathrm{H}\right]$-adrenaline by human platelets. $B r . J$. Pharmacol. 39: 765-778.

14. Murphy, D. L., D. H. Cahan, and P. B. Molinoff. 1975. Occurrence, transport, and storage of octopamine in human thrombocytes. Clin. Pharmacol. Ther. 18: 587-593.
15. Gaut, Z. N., and C. B. Nauss. 1976. Uptake of taurine by human blood platelets: A possible model for brain. In Taurine. R. Huxtable and A. Barbeau, editors. Raven Press, New York. 91-98.

16. Green, A. R., D. J. Boullin, R. Massarelli, and I. Hanin. 1972. Can the human blood platelet be used as a model for the cholinergic nerve ending? Life Sci. 11: 1049-1058.

17. Aminoff, M. J., A. Trenchard, P. Turner, W. G. Wood, and M. Hills. 1974. Plasma uptake of dopamine and 5-hydroxytryptamine and plasma catecholamine levels in patients with Huntington's chorea. Lancet. II: 1115-1116.

18. Barbeau, A., G. Campanella, R. F. Butterworth, and K. Yamada. 1975. Uptake and efflux of 14-C-dopamine in platelets: Evidence for a generalized defect in Parkinson's disease. Neurology. 25: 1-9.

19. Boullin, D. J., and R. A. O'Brien. 1971. Abnormalities of 5-hydroxytryptamine uptake and binding by blood platelets from children with Down's syndrome.J. Physiol. (Lond.). 212: 287-297.

20. Boullin, D. J., and R. A. O'Brien. 1973. The metabolism of 5-hydroxytryptamine by blood platelets from children with Mongolism. Biochem. Pharmacol. 22: 1647-1651.

21. Lott, I. T., T. N. Chase, and D. L. Murphy. 1972. Down's syndrome: Transport, storage and metabolism of serotonin in blood platelets. Pediatr. Res. 6: 730-735.

22. Bayer, S. M., and E. E. McCoy. 1974. A comparison of the serotonin and ATP content in platelets from subjects with Down's syndrome. Biochem. Med. 9: 225-232.

23. Tuomisto, J., and E. Tukiainen. 1976. Decreased uptake of 5-hydroxytryptamine in blood platelets from depressed patients. Nature (Lond.). 262: 596-598.

24. Murphy, D. L., J. R. Mendell, and W. K. Engel. 1973. Serotonin and platelet function in Duchenne muscular dystrophy. Arch. Neurol. 28: 239-242.

25. Coleman, M. 1973. Serotonin in Down's Syndrome. American Elsevier Publishing Co. Inc., New York. 224 pp.

26. Pare, C. M. B., M. Sandler, and R. S. Stacey. 1957. 5-Hydroxytryptamine deficiency in phenylketonuria. Lancet. I: $551-553$.

27. Weiss, H. J., T. B. Tschopp, J. Rogers, and H. Brand. 1974. Studies of platelet 5-hydroxytryptamine (serotonin) in storage pool disease and albinism. J. Clin. Invest. 54: $421-432$

28. Cheng, Y-C., and W. H. Prusoff. 1973. Relationship between the inhibition constant $\left(K_{I}\right)$ and the concentration of inhibitor which causes 50 percent inhibition $\left(I_{50}\right)$ of an enzymatic reaction. Biochem. Pharmacol. 22: 30993108 .

29. Horn, A. S. 1976. Characteristics of transport in dopaminergic neurons. In The Mechanism of Neuronal and Extraneuronal Transport of Catecholamines. D. M. Paton, editor. Raven Press, New York. 195-214.

30. Hunt, P., M-H. Kannengiesser, and J-P. Raynaud. 1974. Nomifensine: A new potent inhibitor of dopamine uptake into synaptosomes from rat brain corpus striatum. $J$. Pharm. Pharmacol. 26: 370-371.

31. Wong, D. T., J. S. Horng, F. P. Bymaster, K. L. Hauser, and B. B. Molloy. 1974. A selective inhibitor of serotonin uptake: Lilly 110140, 3-( $p$-trifluoromethylphenoxy)$N$-methyl-3-phenylpropylamine. Life Sci. 15: 471-479.

32. Smith, L. T., D. R. Hanson, and G. S. Omenn. 1978. Comparisons of serotonin uptake by blood platelets and brain synaptosomes. Brain Res. 146: 400-403.

33. Omenn, G. S., L. T. Smith, and D. R. Hanson. 1978. Pharmacogenetic investigations of platelet uptake of serotonin. III. Serotonin uptake in platelets and in brain synaptosomes from young and aged Macaca nemestrina. In 
Aging in Non-human Primates. D. M. Bowden, editor. Raven Press, New York. In press.

34. Solomon, H. M., N. M. Spirt, and W. B. Abrams. 1970. The accumulation and metabolism of dopamine by the human platelet. Clin. Pharmacol. Ther. 11: 838-845.

35. Boullin, D. J., and R. A. O'Brien. 1970. Accumulation of dopamine by blood platelets from normal subjects and parkinsonism patients under treatment with L-DOPA. Br. J. Pharmacol. 39: 779-788.

36. Drummond, A. H., H. J. Olverman, D. E. MacIntyre, and J. L. Gordon. 1977. Interaction of platelets with serotonin and dopamine. Thromb. Haemostasis. 38: 240A. (Abstr.)

37. Snyder, S. H., and J. T. Coyle. 1969. Regional differences in ${ }^{3} \mathrm{H}$-norepinephrine and ${ }^{3} \mathrm{H}$-dopamine uptake into rat brain homogenates. J. Pharmacol. Exp. Ther. 165: 78-86.

38. Tuomisto, L., J. Tuomisto, and E. E. Smissman. 1974. Dopamine uptake in striatal and hypothalamic synaptosomes: Conformational selectivity of the inhibition. Eur. J. Pharmacol. 25: 351-361.

39. Horn, A. S., A. C. Cuello, and R. J. Miller. 1974. Dopamine in the mesolimbic system of the rat brain: Endogenous levels and the effects of drugs on the uptake mechanism and stimulation of adenylate cyclase activity. J. Neurochem. 22: 265-270.

40. Omenn, G. S., and L. T. Smith. 1978. Platelet uptake of serotonin and dopamine in Huntington disease. Neurology. 28: 300-303. 